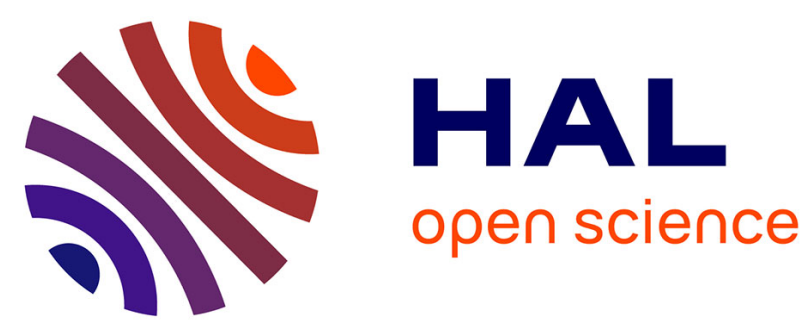

\title{
Synthesis, 3D-structure and stability analyses of NRPa-308, a new promising anti-cancer agent
}

Etienne Brachet, Aurore Dumond, Wang-Qing Liu, Marie Fabre, Mohamed

Selkti, Françoise Raynaud, Olivier Hermine, Rachid Benhida, Philippe

Belmont, Christiane Garbay, et al.

\section{To cite this version:}

Etienne Brachet, Aurore Dumond, Wang-Qing Liu, Marie Fabre, Mohamed Selkti, et al.. Synthesis, 3D-structure and stability analyses of NRPa-308, a new promising anti-cancer agent. Bioorganic and Medicinal Chemistry Letters, 2019, 29 (24), pp.126710. 10.1016/j.bmcl.2019.126710 . hal-02418648

\section{HAL Id: hal-02418648 \\ https://hal-univ-paris.archives-ouvertes.fr/hal-02418648}

Submitted on 19 Dec 2019

HAL is a multi-disciplinary open access archive for the deposit and dissemination of scientific research documents, whether they are published or not. The documents may come from teaching and research institutions in France or abroad, or from public or private research centers.
L'archive ouverte pluridisciplinaire HAL, est destinée au dépôt et à la diffusion de documents scientifiques de niveau recherche, publiés ou non, émanant des établissements d'enseignement et de recherche français ou étrangers, des laboratoires publics ou privés. 


\title{
Synthesis, 3D-structure and stability analyses of NRPa-308, a new promising anti-cancer agent
}

\author{
Etienne Brachet ${ }^{\mathrm{a}, \mathrm{k}}$, Aurore Dumond ${ }^{\mathrm{b}, \mathrm{k}}$, Wang-Qing Liu ${ }^{\mathrm{c}, \mathrm{d}, \mathrm{k}}$, Marie Fabre ${ }^{\mathrm{e}, \mathrm{k}}$, Mohamed Selkti ${ }^{\mathrm{a}}$, \\ Françoise Raynaud $^{\mathrm{d}}$, Olivier Hermine ${ }^{\mathrm{f}, \mathrm{g}, \mathrm{h}}$, Rachid Benhida ${ }^{\mathrm{e}, \mathrm{i}}$, Philippe Belmont ${ }^{\mathrm{a}}$, \\ Christiane Garbay ${ }^{\mathrm{d}}$, Yves Lepelletier ${ }^{\mathrm{f}, \mathrm{g}, \mathrm{h}}$, Cyril Ronco ${ }^{\mathrm{e}}$, Gilles Pagès ${ }^{\mathrm{b}, \mathrm{j}, 1}$, Luc Demange ${ }^{\mathrm{a}, 1, *}$ \\ ${ }^{a}$ Université de Paris, CiTCoM, UMR 8038 CNRS, Faculté de Pharmacie, F-75006 Paris, France \\ ${ }^{\mathrm{b}}$ Centre Scientifique de Monaco, Biomedical Department, 8 quai Antoine Ier, MC-98000, Monaco \\ ${ }^{\mathrm{c}}$ Université de Paris, CiTCoM, UMR 8038 CNRS \& U 1268 INSERM, Faculté de Pharmacie, F-75006 Paris, France \\ ${ }^{\mathrm{d}}$ Université de Paris, LCBPT, UMR 8601 CNRS, UFR Biomédicale des Saints-Pères, F-75006 Paris, France \\ e Université Côte d'Azur, ICN, UMR 7272 CNRS, F-06108 Nice, France \\ I INSERM UMR 1163, Laboratory of Cellular and Molecular Basis of Normal Hematopoiesis and Hematological Disorders: Therapeutical Implications, 24 boulevard \\ Montparnasse, F-75015 Paris, France \\ ${ }^{g}$ Université de Paris, Imagine Institute, 24 boulevard Montparnasse, F-75015 Paris, France \\ ${ }^{\mathrm{h}}$ CNRS ERL 8254, 24 boulevard Montparnasse, F-75015 Paris, France \\ ${ }^{\mathrm{i}}$ Mohamed VI Polytechnic University, UM6P, 43150 BenGuerir, Morocco \\ ${ }^{\mathrm{j}}$ Université Côte d'Azur, UMR 7284 CNRS and INSERM U 1081, Institute for Research on Cancer and Aging (IRCAN), Centre Antoine Lacassagne, 33 Avenue de \\ Valombrose, F- 06189 Nice, France
}

\section{A R T I C L E I N F O}

\section{Keywords:}

Anti-cancer agents

Neuropilins

NRPa-308 synthesis

NRP-a308 stability

\begin{abstract}
A B S T R A C T
We report herein the synthesis of a newly described anti-cancer agent, NRPa-308. This compound antagonizes Neuropilin-1, a multi-partners transmembrane receptor overexpressed in numerous tumors, and thereby validated as promising target in oncology. The preparation of NRPa-308 proved challenging because of the orthogonality of the amide and sulphonamide bonds formation. Nevertheless, we succeeded a gram scale synthesis, according to an expeditious three steps route, without intermediate purification. This latter point is of utmost interest in reducing the ecologic impact and production costs in the perspective of further scale-up processes. The purity of NRPa-308 has been attested by means of conventional structural analyses and its crystallisation allowed a structural assessment by X-Ray diffraction. We also reported the remarkable chemical stability of this molecule in acidic, neutral and basic aqueous media. Eventually, we observed for the first time the accumulation of NRPa-308 in two types of human breast cancer cells MDA-MB231 and BT549.
\end{abstract}

Tumor neoangiogenesis supplies cancer cells in oxygen and nutrients. Moreover, the neoformed blood vessels promote also the dissemination of malignant cells to healthy tissues. Therefore, tackling angiogenesis proved to be a relevant therapeutic option in oncology since more than 30 years. ${ }^{1}$

Tumor angiogenesis results from the over-expression of specific endothelial cell growth factors, among them the pro-angiogenic isoforms of the Vascular Endothelial Growth Factor (e.g. VEGF-A 165 ), which bind simultaneously to the tyrosine kinase receptors VEGF-R1 or VEGF-R2, and to neuropilins (NRPs). ${ }^{2}$ NRPs are multi-partners transmembrane proteins with a non-catalytic cytosolic domain. Although
NRPs have been initially described for binding the semaphorins and for their role in neuronal guidance, their involvement in tumor aggressiveness, angiogenesis, lymphangiogenesis and immune escape is now evidenced. ${ }^{3}$ Moreover, NRPs overexpression is nowadays clinically related to a poor prognosis.

The currently marketed anti-angiogenic drugs, such as Avastin ${ }^{\circledR}$ (a monoclonal antibody directed towards VEGF-A) and Sunitinib ${ }^{\circledR}$ (an ATP mimic targeting the cytosolic domain of tyrosine-kinase involved in angiogenesis), prevents the interaction between VEGF- $\mathrm{A}_{165}$ and its receptors VEGF-R1 or VEGF-R2 or directly inhibits their kinase activity, respectively. However, despite indisputable transient benefits for

\footnotetext{
* Corresponding author.

E-mail address: luc.demange@parisdescartes.fr (L. Demange).

${ }^{\mathrm{k}}$ These authors contributed equally to this work.

${ }^{1}$ These authors co-directed the work.
} 
<smiles>CCOc1ccccc1NC(=O)c1ccc(C)c(S(=O)(=O)Nc2ccc(C)cc2)c1</smiles>

\section{NRPa-308 anti-proliferative activity : \\ $I_{50}(48 \mathrm{~h}) \quad$ MDA-MB231: $4.9 \mu \mathrm{M} \quad \mathrm{IC}_{50}(72 \mathrm{~h})$ MDA-MB231:0.2 $\mu \mathrm{M}$ BT549 : $2.1 \mu \mathrm{M} \quad$ BT549: $0.1 \mu \mathrm{M}$}

\section{Sunitinib anti-proliferative activity :}

\section{$\mathrm{IC}_{50}(48 \mathrm{~h})$ MDA-MB231 : $2.6 \mu \mathrm{M}$ BT549 :2.2 $\mu \mathrm{M}$ \\ $I_{50}(72 h)$ \\ MDA-MB231 : $3.7 \mu \mathrm{M}$ BT549 : $3.5 \mu \mathrm{M}$}

Chart 1. Structure of NRPa-308, and its antiproliferative activity against two breast cancer cell lines (MDA-MB-231 and BT549) measured after $48 \mathrm{~h}$ and $72 \mathrm{~h}$ treatment and compared to these of the marketed drug Sunitinib ${ }^{\circledR}$. These values have been reported by us in ref. [7].

patients, these therapies are not curative; tumors always relapse and become more aggressive, highlighting the real need for alternative therapeutic strategies. ${ }^{4}$ Thereby, in the continuation of our ongoing research in the development of new and potent anticancer agents, ${ }^{5}$ we have focused our attention on NRPs as targets, ${ }^{6}$ and we have recently disclosed NRPa-308 (Chart 1, Compound 1), a small-sized antagonist of the interaction between VEGF- $\mathrm{A}_{165}$ and NRPs. ${ }^{7}$ NRPa-308 exerts remarkable anti-angiogenic and anti-proliferative effects in vitro IC $_{50}$ in the $10 \mathrm{nM}$ range against a large panel of solid and hematological malignancies). Moreover, in our experimental models of nude mice xenografted with human triple negative breast cancer cells (MDAMB231), NRPa-308 reduces the tumor growth by more than $60 \%$, and enhances significantly animal survival. In addition, this molecule has no acute toxicity in treated animals.?

Altogether, these results underline the high potential of NRPa-308 for opening new avenues in anticancer strategies. Thus, we report herein a straightforward synthesis allowing a gram scale production of this molecule. Interestingly, this optimized process does not require intermediate time-consuming purification steps. We also demonstrate the chemical stability of this promising anticancer agent and its significant accumulation in two types of human breast cancer cells (MDAMB231 and BT549).

Although NRPa-308 may be described as a "simple" molecule (MW $=424 \mathrm{~g} / \mathrm{mol}$, three aromatic rings connected by sulphonamide and amide linkages), it is noteworthy that its large-scale synthesis faces difficulties. This challenge is mainly due to similar synthetic pathways for accessing amide and sulphonamide bonds. Therefore, we decided to smoothly condense successively the required substituted anilines to the central ring, using the commercially available methyl $p$-toluate as starting material.

Our initial approach is outlined in Scheme 1; the first step consists in the sulfonylation of the methyl $p$-toluate. In fact, despite its apparent chemical simplicity, this reaction is poorly exploited due to its experimental difficulty. ${ }^{8}$ To illustrate this paradox, one can mention the recent work of Singh and co-workers who reported a three-steps process of $p$-toluate sulfonylation through a time-consuming pathway, including successive saponification and re-esterification. ${ }^{9}$ However, we decided to react commercially available methyl $p$-toluate with one equivalent of chlorosulfonic acid under solvent-free conditions to intend the mono-sulfonyl chloride derivative 2. Different experimental conditions have been tested. We studied the influence of the load of chlorosulfonic acid (from 1.5 eq. until 0.5 eq.) and the influence of the temperature (from $50{ }^{\circ} \mathrm{C}$ to $130{ }^{\circ} \mathrm{C}$, since methyl $p$-toluate melts at $35^{\circ} \mathrm{C}$ ). The best conversion was observed by heating methyl $p$-toluate with 1.1 eq. of chlorosulfonic acid at $120^{\circ} \mathrm{C}$ for $4 \mathrm{~h}$. Nevertheless, this sulfonylation has always led to a mixture of compounds difficult to separate, which consisted of: (i) the expected sulfonyl chloride product 2; (ii) the dichlorinated compound $\mathbf{3}$, and (iii) the remaining unreacted methyl $p$-toluate. With these optimized conditions, the analytic monitoring allowed to estimate the ratio methyl $p$-toluate/2/3 as about $1 /$ $1 / 3$.

This crude material was hydrolysed overnight using $2 \mathrm{~N}$ aqueous $\mathrm{HCl}$ in refluxing toluene with tetrabutylammonium bromide as a phasetransfer catalyst. ${ }^{10}$ Although this method is known to hydrolyse selectively a carboxyl chloride $v s$ a sulfonyl chloride, this was not the case here since a part of compound $\mathbf{2}$ has been fully hydrolysed, affording the carboxyl-sulfonic diacid 4 , which was isolated from the aqueous layer ( $49 \%$ yield). On the other hand, evaporation of the remaining organic layer provided a mixture of a solid containing compound $\mathbf{2}$ and the unreacted methyl $p$-toluate ( $20 \%$ yield), and compound 3 as an oil. The two layers were separated by filtration. Unpurified compound 2 was coupled with $p$-toluidine using catalytic amounts of DMAP to afford sulfonamide $5,{ }^{11}$ which was then saponified to provide 6 after acidification. The $p$-toluic acid resulting from the unreacted methyl $p$-toluate was removed at this step by repeated trituration in diethyl ether affording compound 6 as a pure white solid (31\% yield). The coupling of 6 with 2-ethoxyaniline using BOP/DIEA in DMF led to the final expected compound 1 (NRPa-308) in 73\% yield.

According to this process, the recycling of $\mathbf{4}$ provided an alternative route to compound 1 (Scheme 1). Indeed, compound 4 was treated with $o$-ethoxyaniline in presence of BOP/DIEA. The resulting compound 7 was obtained in $62 \%$ yield, and treated with thionyl chloride at room temperature, ${ }^{12}$ it afforded a chloro-sulfonic acid derivative, which was directly condensed with $p$-toluidine in the presence of catalytic DMAP. Following this pathway, compound 1 was obtained in 24\% yield (over two steps). Although this process does not require any purification step, which is very important to speed up a synthesis, it does not allow any scale-up, since the desired product was obtained in less than $10 \%$ yield from the commercial starting material.

Therefore, we have considered the alternative synthetic route outlined in Scheme 2. According to this second pathway, the target compound 1 may be obtained in only three steps from $p$-methylbenzoic acid as commercially available starting material. The chlorosulfonylation has been conveniently performed by heating $p$-methylbenzoic acid in chlorosulfonic acid at $100^{\circ} \mathrm{C}$. The reaction occurs overnight, however the subsequent work-up requires a sustained attention. Indeed, the mixture should be cautiously ice-quenched to avoid an exothermic behaviour leading to the formation of side-products. After the

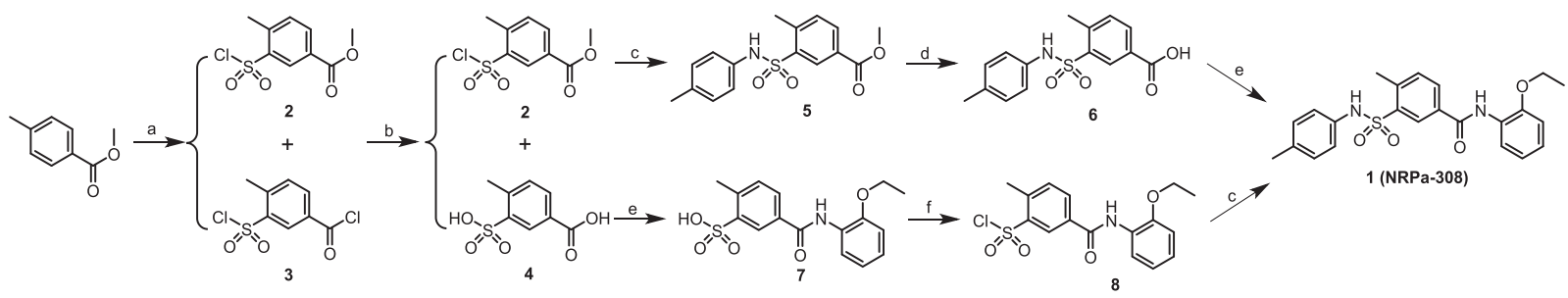

Scheme 1. Reagents and conditions (a): $\mathrm{ClSO}_{3} \mathrm{H}, 120^{\circ} \mathrm{C}, 4 \mathrm{~h}$; (b): $2 \mathrm{~N}$ aq. $\mathrm{HCl}, n \mathrm{Bu}_{4} \mathrm{~N}^{+} \mathrm{Br}^{-}$, toluene, reflux overnight; (c): $p$-toluidine, DIEA, DMAP, CH${ }_{3} \mathrm{CN}$, R.T. overnight; (d) $2 \mathrm{~N}$ aq. $\mathrm{NaOH}, \mathrm{MeOH}, 3$ h, R.T; (e): 2-ethoxyaniline, BOP, DIEA, DMF, R.T. overnight; (f): $\mathrm{SOCl}_{2}$, DMF, rt, overnight. 


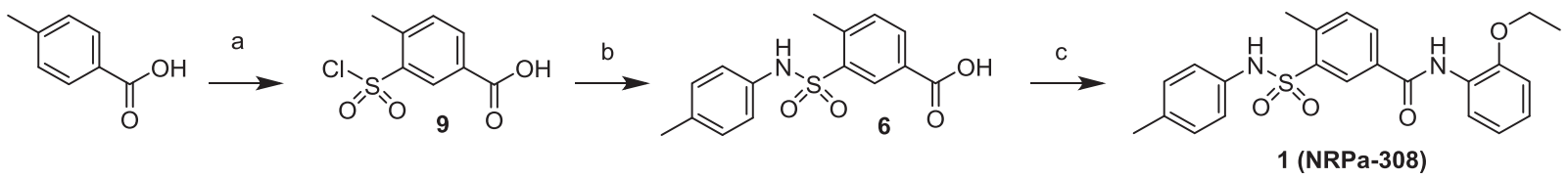

Scheme 2. Reagents and conditions (a): $\mathrm{ClSO}_{3} \mathrm{H}, 100^{\circ} \mathrm{C}, 12 \mathrm{~h}$; (b): p-toluidine ${ }^{-}$, DCM, $0{ }^{\circ} \mathrm{C}-\mathrm{rt}$. 1 h; (c): o-ethoxyaniline, EDCI, DIEA, DMF, R.T. overnight.

neutralization of the unreacted chlorosulfonic acid, conventional filtration and water washing afforded 9 as a white solid in $84 \%$ yield. The unpurified product was directly reacted at $0{ }^{\circ} \mathrm{C}$ in dichloromethane with $p$-toluidine for one hour to afford the bi-aryl sulfonamide 6 . The expected product was isolated as a pure solid after acidic treatment and extraction (78\% yield). ${ }^{1} \mathrm{H}$ NMR provided evidence that no purification was required at this step. Eventually, compound 6 has been reacted according to a conventional process with $o$-ethoxyaniline (1.1 eq.) in the presence of EDCI (1.1 eq) as coupling agent and diisopropylethylamine (3.1 eq.) as base. This last reaction has been completed overnight, and it afforded after treatment and purification by flash chromatography the expected NRPa-308 (1) as a pure white solid (64\% yield).

To summarize, this second synthetic route afforded NRPa-308 1 in shortened reaction times and at the gram scale (global yield from the commercially available starting material: $42 \%$ ). Another key feature is the absence of intermediate purifications, which reduces the ecologic impact and the production costs of the synthesis (no use of large amount of toxic solvents requiring recycling).

In addition, single crystals of NRPa-308 1 were obtained from hot toluene, and a suitable one was selected for X-Ray 3-D structure determination. The experimental procedure is depicted in the Supporting Information section. Briefly, the structure was solved by direct method using SHELXS ${ }^{13}$ refinement, based on $\mathrm{F}^{2}$ was carried out by full matrix least squares using SHELXL-2018 ${ }^{14}$ software with anisotropic displacement parameters for all non-hydrogen atoms. Hydrogen atoms were located on a difference Fourier map and introduced into that calculations as a riding model with isotropic thermal parameters. All calculations were performed by using the Crystal Structure crystallographic software package WINGX. ${ }^{15}$

NRPa-308 1 has a molecular structure built from entities, depicted in Fig. $1 .{ }^{16}$ The crystal data collection and refinement parameters are collected in Table S1 (Supporting Information section). CCDC-1939102 contains the supplementary crystallographic data for this paper, which can be obtained free of charge from the Cambridge Crystallographic Data centre.

Briefly, at the single molecular level, the two aromatic rings linked thanks to the amide bond appear rather coplanar, while the third one, connected by the sulphonamide linker, is twisted, rather perpendicular to the central aromatic ring. At the supramolecular architecture level, neutral molecules are associated in the crystal essentially via $\mathrm{N}-\mathrm{H}^{\cdots} \mathrm{O}$ hydrogen bonds in a three-dimensional way. More precisely, two hydrogen bonds involving three close molecules are evidenced in this structure: (i) the first involves the $\mathrm{NH}$ "amide" of the "central" molecule, and an oxygen of the sulfoxide linker belonging to an adjacent molecule; (ii) the second takes place between the NH "sulfonamide" of the "central" molecule and the oxygen of the amide belonging to a third molecule. In the continuation of this structural analysis, we plan now to crystalize NRPa-308 1 with NRP-1 to decipher the close contacts between the antagonist and its receptor.

We next focused our attention on NRPa-308 1 chemical stability. Interestingly, we reported formerly that the anti-proliferative activities of NRPa-308 are deeply related to its incubation times with the tumor cells (Chart 1). ${ }^{7}$ Thus, our purpose was to unambiguously demonstrate that these anti-proliferative effects are solely due to NRPa-308, and not to one of its potential metabolites or one of its degradation products.

First, the chemical stability of NRPa-308 was assayed by HPLC analysis at three different $\mathrm{pH}(0.9,7.4$ and 8.4$)$ and at two temperatures
$\mathbf{A}$

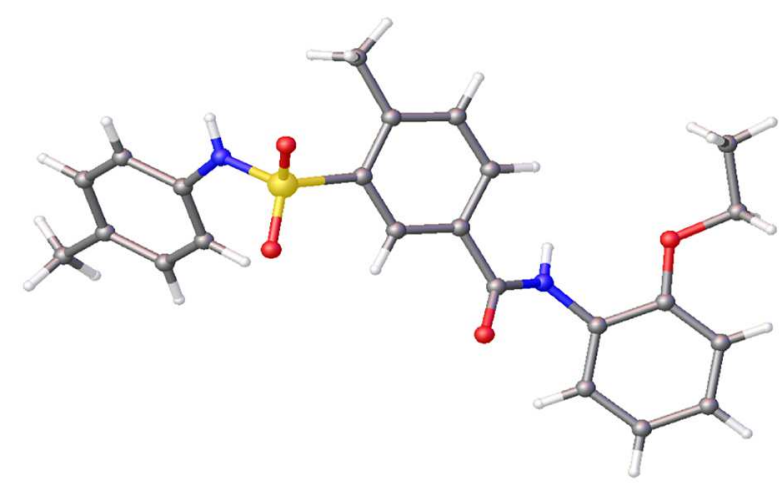

B

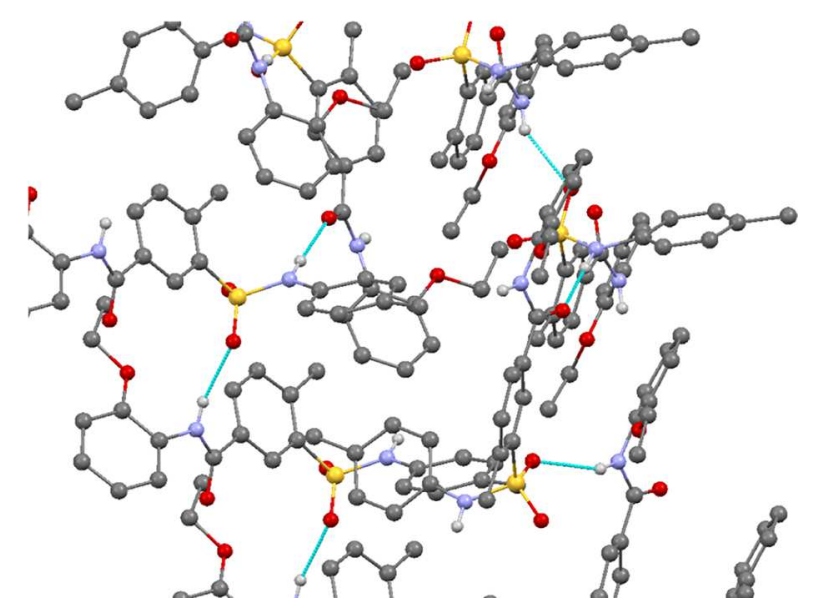

Fig. 1. Structure of NRPa-308 1 analysed by X Ray. Please refer to reference [16], and to the Supporting Information section for more details. A: Single crystal of Nrp-a308 1; B: Supramolecular arrangement of Nrp-a308 1.

$\left(25^{\circ} \mathrm{C}\right.$ and $37^{\circ} \mathrm{C}$ ). After 16 days, the compound proved fully stable under all these conditions (Fig. 2, the detailed experimental procedures are given in the Supporting Information section).

Next, we studied the stability of NRPa-308 in cellular culture media, in presence of malignant cells. To this end, MDA-MB-231 and BT-549 breast cancer cells were cultured in the presence of $2 \mu \mathrm{mol}$ of NRPa-308 for three days, and the HPLC analyses of the supernatant revealed that NRP-a308 was not degraded (Fig. S1, Supporting Information section). Then, the cells were washed and lysed with methanol. The lysates were extracted with $\mathrm{CHCl}_{3} / \mathrm{MeOH}, 9 / 1$, v/v and quantitatively analysed by HPLC. In both cases, NRPa-308 proved stable, with no other peak detected (Fig. 3, the detailed experimental procedures are given in the Supporting Information section). Therefore, the in vitro antiproliferative activities, already measured by us (Chart 1 ), are due to compound 1 and not due to one of its metabolites or degradation products.

In addition, the quantitative dosage revealed a significant accumulation of NRPa-308 in cells, with respectively $5.14 \pm 0.06 .10^{-9}$ mol and $1.40 \pm 0.01 .10^{-9} \mathrm{~mol}$ calculated in MDA-MB231 and BT549 cells, after three days. Indeed, NRPa-308 mimics the interaction between NRP-1 and the endogenous tetrapeptide TKPR, so-called tuftsin. 

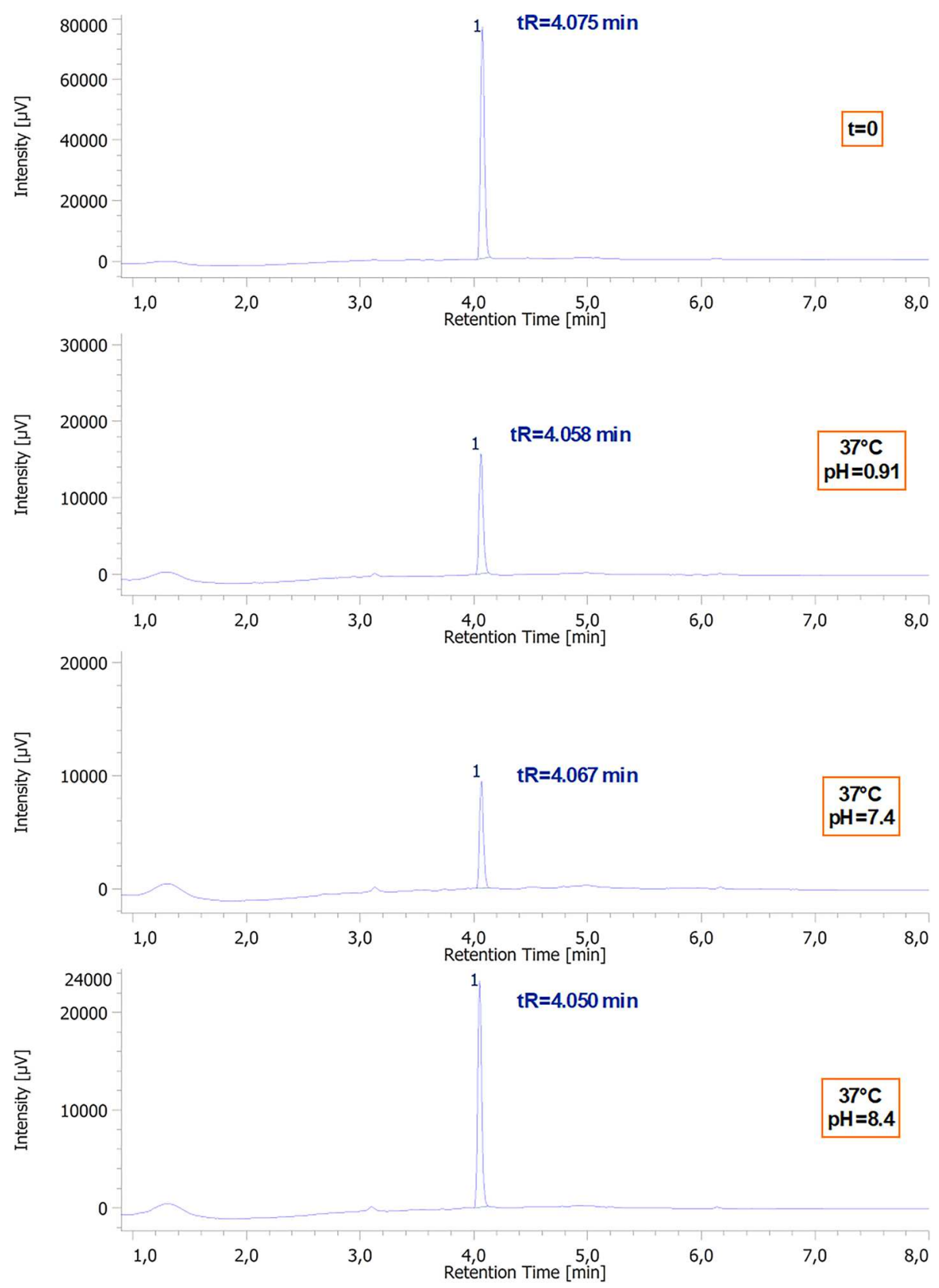

Fig. 2. Chromatograms showing the stability of NRPa-308 in aqueous buffers at $\mathrm{pH} 0.9,7.4$ and 8.4 after 16 days incubation at $37^{\circ} \mathrm{C}$.

Tuftsin has been used as model for the development of penetrating peptides able to interact with the VEGF-A 165 /NRP-1 hotspot. ${ }^{17 \mathrm{~b}}$ The tufstin-derivative penetrating peptides respect the $\mathrm{C}$-terminus sequence $\mathrm{R} / \mathrm{K} / \mathrm{XXR} / \mathrm{K}$ (so called: C-end rule or CendR). They interact thereby with NRP-1, and are internalized into the cells thanks to the NRP-1 transmembrane trafficking. Based on this mechanism, peptide carriers (iRGD peptides) for selective drugs delivery have been recently disclosed. The iRGDs carriers are short-sized cyclic peptides, whose cleavage by integrins deliver a "C-end rule" sequence, able to be internalized into cells by NRP-1. ${ }^{18}$ The iRGDs are used to selectively address inside malignant cells potential therapeutic agents, such as small-sized molecules (e.g. doxorubicin) or siRNAs. ${ }^{19}$ However, at the best of our knowledge, non-peptidic small-sized NRP-1 antagonists have ever been reported for a potential "iRGD" like vectorization process. Thus, this result might constitute a way for the development of a new class of nonpeptidic compounds able to selectively address therapeutic agents into the tumor cells through NRP-1.
To conclude, we report herein an expeditious synthesis for the newly identified anti-cancer agent NRPa-308. Our strategy is based on a three steps procedure, and it requires neither intermediate purification nor use of expensive reactants, which is of utmost interest for the development of further large-scale production. The structure of this molecule has been unambiguously characterised thanks to X-Ray crystallography, and the three-dimensional supramolecular architecture of the crystal is granted by $\mathrm{N}-\mathrm{H}^{\cdots} \mathrm{O}$ hydrogen bonds between three adjacent molecules. We also observed the acute stability of this molecule in different media, which proved that its remarkable cytotoxic effects against cancer cells is not imputable to any of its potential metabolites. Lastly, we report the significant accumulation of NRPa-308 into cancer cells, which might be related to the transmembrane trafficking properties of NRP-1. 

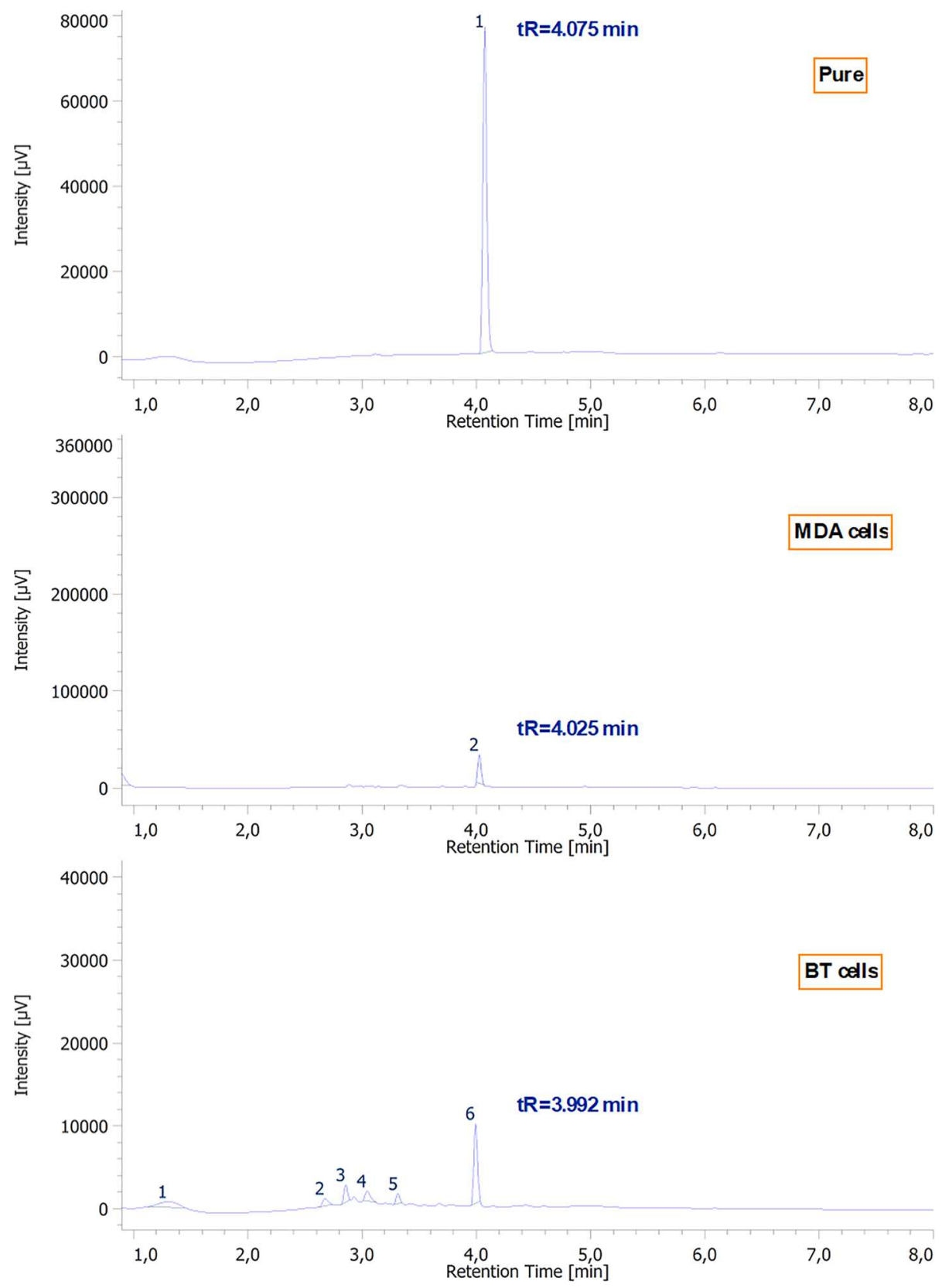

Fig. 3. Chromatograms showing the metabolism of NRPa-308 in MDA-MB231 and BT549 cells after three days incubation at $37{ }^{\circ} \mathrm{C}$.

\section{Acknowledgements}

This work has been supported by the French Government through the UCA ${ }^{\mathrm{JEDI}}$ investments, and through the National Research Agency (ANR), with the reference number ANR "TARMAC" ANR-17-CE170011-03 (MF PhD grant). Also, we are grateful to the financial support from ANR "GOLDWAR" ANR-16-CE07-0006-02. This study was conducted as part of the Centre Scientifique de Monaco Research Program, funded by the Government of the Principality of Monaco. This work was supported by the Helsinn company (AD PhD grant) (https://www.helsinn.com/). This article is based upon work form COST Action CA15135, supported by COST.

\section{Appendix A. Supplementary data}

Supplementary data to this article can be found online at https:// doi.org/10.1016/j.bmcl.2019.126710.

\section{References}

1. a) Arezumand R, Alibakhshi A, Ranjbari J, Ramazani A, Muyldermans S. Front Immunol. 2017;8:1746/1-1746/13;

b) Martin AR, Ronco C, Demange L, Benhida R. Med Chem Commun. 2017;8:21-52; c) Frandsen S, Kopp S, Wehland M, Pietsch J, Infanger M, Grimm D. Curr Pharm Des. 2016;22:5927-5942.

2. a) Bergantino F, Guariniello S, Raucci R, et al. Biochim Biophys Acta. 1854;2015:410-425;

b) Horowitz A, Seerapu HR. Cell Signal. 2012;24:1810-1820;

c) Ferrara N, Gerber HP, LeCouter J. Nat Med. 2003;9:669-676.

3. a) Roy S, Bag AK, Singh RK, Talmadge JE, Batra SK, Datta K. Front Immunol 2017;8:1228/1-1228/27;

b) Guo HF, Vander Kooi CW. J Biol Chem. 2015;290:2912-2916;

c) Prud'homme GJ, Glinka Y. Oncotarget. 2012;3:921-939;

d) Jubb AM, Strickland L, Liu SD, Mak J, Schmidt M, Koeppen H. J Pathol 2012;226:50-60

e) Koch S. Biochem Soc Trans. 2012;40:20-25;

f) Grandclement C, Borg C. Cancers. 2011;3:1899-1928.

4. a) Spanheimer PM, Lorenzen AW, De Andrade JP, et al. Ann Surg Oncol. 2015;22:4287-4294;

b) Gaumann AK, Kiefer F, Alfer J, Lang SA, Geisser EK, Breier G. Int J Cancer. 
2016;138:540-554;

c) Giuliano S, Cormerais Y, Dufies M, et al. Autophagy. 2015;11:1891-1904.

5. a) Dufies M, Grytsai O, Ronco C, et al. Theranostics. 2019. https://doi.org/10.7150/ thno.35032;

b) Marzag H, Zerhouni M, Tachallait H, et al. Bioorg Med Chem Lett. 2018;28:1931-1936;

c) Allaoui S, Dufies M, Driowya M, et al. Bioorg Med Chem Lett.

2017;27(9):1989-1992;

d) Ronco C, Martin AR, Demange L, Benhida R. Med Chem Commun. 2017;8(2):295-319;

e) Houzé S, Hoang NT, Lozach O, et al. Molecules. 2014;19(9):15237-15257.

6. a) Jarray R, Pavoni S, Borriello L, et al. Biochimie. 2015;118:151-161;

b) Liu WQ, Borriello L, Allain B, et al. Int J Pept Res Ther. 2015;21(1):117-124;

c) Goldwaser E, DeCourcy B, Demange L, et al. J Mol Model. 2014;20(11):1-24;

d) Borriello L, Montès M, Lepelletier Y, et al. Cancer Lett. 2014;349(2):120-127;

e) Liu WQ, Megale V, Borriello L, et al. Bioorg Med Chem Lett. 2014;24(17):4254-4259.

7. Liu WQ, Lepelletier Y, Montes M, et al. Cancer Lett. 2018;414:88-98.

8. a) Abbavaram BRA, Reddyvari HRV. J Kor Chem Soc. 2013;57:731-737;

b) Kendall JD, Giddens AC, Tsang KY, et al. Bioorg Med Chem. 2012;20:58-68;

c) Zhang R, Lei L, Xu YG, Hua WY, Gong GQ. Bioorg Med Chem. 2007;17:2430-2433.

9. Singh R, Bordeaux M, Fasan R. ACS Catal. 2014;4:546-552.

10. Ashikawa M, Sakagami S. JP 2009167142, 2009.

11. Hadj-Slimane R. WO 2015004212, 2015.
12. Jenkis TJ, Guan B, Dai M, et al. J Med Chem. 2007;50:566-584.

13. Sheldrick GM. SHELXS-97, Program for Crystal Structure Solution. Göttingen, Germany: University of Göttingen; 1997.

14. Sheldrick GM. Acta Crystallogr, Sect A: Found Crystallogr. 2008;64:112-122.

15. Farrugia LJ. J Appl Cryst. 1999;32:837.

16. Crystal data and structure refinement for NRPa-308: Orthorhombic crystal, space group P212121 (no. 19), a = 7.8694(2) $\AA, b=14.9423(5) \AA, c=17.9015(5) \AA, v$ $=2104.98(11) \AA 3 . \mathrm{Z}=4, \mathrm{~T}=100(2) \mathrm{K}, \mu(\mathrm{CuK \alpha})=1.597 \mathrm{~mm}-1$, Dcalc $=1.339 \mathrm{~g} /$ $\mathrm{cm} 3,23575$ reflections measured $\left(7.706^{\circ} \leq 2 \Theta \leq 133.216^{\circ}\right), 3719$ unique (Rint $=$ 0.0396 , Rsigma $=0.0264$ ) which were used in all calculations. The final R1 was 0 . $0252(\mathrm{I}>2 \sigma(\mathrm{I})$ ) and wR2 was 0.0617 (all data). More details are provided in the Supporting Information section.

17. a) Zanuy D, Kotla R, Nussinov R, et al. J Struct Biol. 2013;182:78-86;

b) Teesalu T, Sugahara KN, Kotamraju VR, Ruoslahti E. Proc Natl Acad Sci USA. 2009;106:16157-16162.

18. a) Roth L, Agemy L, Kotamraju VR, et al. Oncogene. 2012;31:3754-3763;

b) Ye Y, Zhu L, Ma Y, Niu G, Chen X. Bioorg Med Chem Lett. 2011;21:1146-1150;

c) Fu KF, Zhang WQ, Luo LM, et al. Int J Nanomed. 2013;8:2473-2485;

d) Sugahara KN, Teesalu T, Karmali PP, et al. Cancer Cell. 2009;16:510-520.

19. a) Liu H, Shi X, Wu D, et al. ACS Appl Mater Interfaces. 2019;11:19700-19711;

b) Ding N, Zou Z, Sha H, et al. Nat Commun. 2019. https://doi.org/10.1038/s41467019-09296-6;

c) Barman S, Das G, Gupta V, et al. Mol Pharm. 2019;16:2522-2531;

d) Lo JH, Hao L, Muzumdar MD, et al. Mol Cancer Ther. 2018;17(11):2377-2388. 